Journal of Education and Vocational Research

Vol. 1, No. 3, pp. 96-105, June 2011

\title{
Enhancing the Study of Business Statistics with an e-Homework System
}

\author{
*Clare Chua-Chow, Carole A. Chauncey, Doug McKessock \\ Ted Rogers School of Management, Ryerson University, Toronto, Ontario M5G 2C5, Canada \\ *cchua@ryerson.ca
}

\begin{abstract}
This paper compares the performance of two classes of students who were enrolled in an Introductory Business Statistics course. Students in one class were required to use e-homework, an online system and another class completed their homework assignments without the online system. The major objective of this study was to determine whether there was any difference in the level of performance between students who used the online homework system and those who did homework assignments in the traditional method. The students in a large class with online homework were compared to students without online homework. This e-homework system enables instructors to monitor individual student's performance and transmit immediate feedback to students. This paper answers the question: Can online homework improve the performance of students enrolled in an Introductory Business Statistics course? To answer this question, we evaluated the students' performance based on their final grades in a first year Introductory Statistics course. Students' perceptions of the usefulness of online homework were also considered. The findings of this research showed that students obtain many benefits from online homework. Students were better prepared in writing test, their ability to understand course concepts increased because of the timely feedback they receive from instructors, discussion about Statistics among peers occurred more frequently than in previous semesters. Students cultivated better study habits, and consequently, they developed more confidence in applying their knowledge of statistical concepts.
\end{abstract}

Keywords: Online homework, student performance, learning, technology pedagogy

\section{Introduction}

The intent of this research is to explore whether access to an e-homework system can improve student learning in business statistics. Over the years, lectures and in-class assignments have not significantly increased student interest in the course or enhanced their understanding of course concepts. In order to apply and reinforce their knowledge of course concepts, students must complete numerous problems related to each topic. A well designed e-homework system such as the one used in this class, would provide students with the unlimited opportunities to redo assignments until they understand how to solve each type of problem. This research compares the performance of students who completed their assignments online to the performance of those students who did not use the online system to do their assignments. This research strives to find a viable solution that will alleviate the difficulty students experience when taking business statistics, a required course in the Business Management program. The e-homework system enables students to repeatedly review tutorials, receive instant feedback, correct their mistakes immediately, and to transfer their understanding of concepts to different sets of data. The consequences of these e-homework system capabilities will indicate its level of effectiveness on students' performance.

Most students think Business Statistics is difficult to comprehend. They consider it as being very abstract, having a steep learning curve, requiring numerous assignments, and difficult to apply to business scenarios. These perceptions have maligned business statistics courses to the extent that they are among the least understood and the most feared courses in an undergraduate Business Management curriculum. Consequently, teaching business statistics is challenging because these perceptions influence students' participation in class, their willingness to persist throughout the semester, their final grades as well as their propensity to utilize statistical concepts in their business careers (Jordan and Stroup, 1984; Swanson, Meinert, and Swanson, 1994; Zanakis and Valenzi, 1997). This is indeed unfortunate because the ability to conduct statistical analysis is one of the skills business organizations value very highly (Lane el at., 1993; Philip and Schulz, 1994). Instructors are concerned about the high failure rates, the high anxiety levels and the general low performance of students in these courses. For several years researchers have discussed the 
need for changes in statistical education (Brightman, 1977; Garfield et al., 2002; Harrington and Schibik, 2004). In response to this dilemma, many Business programs have undertaken different teaching strategies such as, other approaches to pedagogy, restructured their curricula, while others have changed their delivery modes, with the intent of improving student performance (Zanakis and Valenzi, 1997). The primary goal of homework is to enable students to understand and retain course material at the time it is being taught (Smolira, 2008). The prevalence of online homework systems indicates the potential for these systems to supplement both teaching and learning. This investigation enables the researchers to study how instructors may be overcome the challenges they face teaching Business Statistics. As class size continues to increase, so will the number of student failures, unless research such as this current one provides the mechanisms for alleviating the problems.

In an attempt to teach large classes of over 700 students, reduce the high failure rate, and the limited resources which are provided to teach the course, we decided to automate the homework component of the first year, introductory statistics course. Although research on the effectiveness of homework has had mixed results, (Peters et al., 2002), most studies have concluded that assigned and graded homework has positive impact on student performance and learning (Rayburn and Rayburn, 1999; Cooper et al.;. 2006). We decided that homework is vital to the deep learning of statistical concepts. It reinforces classroom learning, and is required for the development of skills and the acquisition of subject knowledge. Furthermore, most educators believe that homework is an important part of the daily education routine. The findings of this research provide an alternative solution to this ongoing problem.

\section{Literature Review}

E-Homework (e-HW') is the automated homework system which was developed and implemented to achieve the learning outcomes of the first year introductory business statistics course. The advent of new technologybased pedagogy has revamped how educators deliver and teach course content. It has also played an important role in the assignment of homework. This paper focuses on assigning and managing the ehomework component of a course which is taught in the face-to-face classroom setting. The online homework system has been largely used in a variety of courses such as Physics (Bonham et al., 2001; Cheng et al. 2004; Peng, 2006; Smolira, 2008), Finance (Biktimirov and Klassen, 2008; Cudd et al., 2004; Smolira, 2008), Accounting (Peng, 2009), Economics (Lee, 2010), Mathematics (Hauk and Segalla, 2005; Glass and Sue, 2008; Burch and Kuo, 2010), Sciences (Penn et al., 2000; Hall et al. 2001; Dufresne, et al. 2002; Bonham et al., 2003; Cole and Todd, 2003; Allain and Williams, 2006 and Cooper et. al. 2007) and Operation Management (Houts and Taylor, 2008; Peters et al., 2002).

In reviewing the literature on the various type of online homework system, we found that the system can be developed either by the educators themselves to meet their own needs or by the publishers who now provide online homework system bundled with the textbook, for example, Pearson/Addison-Wesley's Course Compass (Cooper et al 2007). In his paper on Student Perception of Online Homework in Introductory Finance Courses, Smolira (2008) discusses the availability of online homework facilities Homework Manager and Thomson NOW, which are designed by McGraw-Hill/Irwin and Thomson/South-Western respectively. The literature indicates that Web Assign, an online instructional tool system for both students and instructors, was developed at North Carolina State University, is used extensively by more than three hundred (300) schools and tertiary institutions throughout the US. The wide-spread use of Web Assign is an indication of demand for such a system. The capability of the online system to grade homework assignments, allows instructors to concentrate on other teaching related activities such as the distribution, collection, and recording of assignments quickly and accurately over the internet. Without this online homework system, in some schools, teachers have neither the time nor resources to check homework daily.

\section{E-Homework System}

Online homework systems have different features. Some systems have multiple choice format type of questions (Johnston, 2004), while others are Wed-CT-based. The Web-Based Homework developed by Packard and Holmes (1993), Penn et al. (2000), Lee and Heyworth (1997); Thoennessen and Harrison (1996), Bonham et al. (2003), and Kortemeyer (2006) differ from the one developed by us. Our system, e- 
Homework, provides many of the same features as Web Assign, however it is unique. For example, every student is given a different set of data for the same set of questions. If two students have the same homework question, each student is given a different set of data for the same question. The format of questions is short answer type of question. This limits the free riding problem but however it does encourage discussions among students. The main objectives for developing a dynamic homework system were a) to expedite the grading of homework assignments of students in a large class of more than seven hundred (700) students, b) to accelerate the rate of providing feedback to the large class in a timely manner, and c) to evaluate students' progress in the course. Prior to the implementation of e-Homework it was not feasible to manually grade assignments, provide feedback and monitor student progress in a timely manner. These are all activities which are critical to student learning. In one year, when instructors assigned homework problems without grading them, students lacked motivation and did not even attempt the homework. Consequently, students' performances were poor. Realizing this, we developed a system where the assignments were posted online, graded online, solutions available online, and immediate feedback was made available to the students. There is no doubt that our online homework system provides the instructor with a chance to monitor the individual student's performance individually as well as it provides effective feedback to instructor.

It is important to evaluate the homework system from the students' perspective as well as from perspective of how it impacts them. Our e-Homework system has moved a significant portion of the time spent on assignments, homework, testing and grading, and feedback activities out of the classroom. The increased class time is now spent doing in-class discussions and interactions which allows students to develop a greater appreciation for the course and it role in Business and Society as a whole. Findings from studies have shown that the online homework benefited the students by increasing test scores and elevating their confidence in taking examination (Penn et al., 2000). In general, online homework has resulted in a positive outcome on student performance and learning (Lee and Heyworth, 1997; Thoennessen and Harrison, 1996; Sasser, 1991; and Wong, 2001).

The objectives of automating homework were to provide unlimited access to problems which require frequent reviews and practice, to the availability of course materials in the event students were absent from class, to provide feedback in real-time which enables students to recognize their mistakes and correct them, to elimination of the easiest form of cheating by randomizing the questions; and most importantly, and to improve grades. The benefits of these objectives are;

- By generating individualized questions that have different numerical values but are based on the same concepts deters students from just copying answers. Students may discuss the course methodologies with their classmates however they have to apply the concepts according to the requirements of the specific question. This approach eliminates the problem of copying answers.

- Access to individualized homework on the internet, increases the number of sessions students can practice working on questions until they achieve a sound understanding of the concepts. This allows students to work in private and develop their confidence in their performance.

- When the computer marks questions and generates suggestions for correcting wrong answers, students receive feedback that is directly related to their weaknesses. The feedback is personalized. The suggestion reports reduces the class time which the instructor would have had to spend counseling individual students

- The feedback from the e-homework system intervenes in student's learning as soon as the deficiencies in their understanding are detected and before they affect the learning of subsequent material or test results. This eliminates the "ripple effect" the deficiencies can exert on the learning of subsequent concepts.

- The e-Homework system identifies homework questions which are done poorly by a large proportion of students. This capability enables the instructor to adjust the current lecture and provide clarifications in a timely fashion

Evaluating the e-Homework System: The online homework system can be a time saver to instructors who have a large enrollment of students in the class, but whether students benefit from using this system needs to be investigated. Overall, is the e-homework effective, in terms of student performance, attitudes, and retention, compared to its classroom-based counterparts? We measure the effectiveness of the e-homework 
system from two perspectives:

- $\quad$ The impact of online homework on students' performance

- $\quad$ The students' attitudes, in terms of satisfaction of the e-homework system

\section{Hypotheses}

Based on the above research objectives, the following hypotheses were formulated to evaluate the effectiveness of our e-homework system developed to enable students' learning.

Hypothesis 1: There is difference in final marks between the class with e-homework and the class without e-homework.

Hypothesis 2: There is relationship between grade distribution and type of class (class with ehomework and class without e-homework).

Hypothesis 3: The participation rate for the e-homework has an impact on the final grade.

Hypothesis 4: The proportion of students who are satisfied with the online homework system is more than half.

To test the hypotheses, we conducted a study involving two classes in which the Introductory Statistics were taught by the same professor. The professor used the same course outlines with the same evaluation components and used the same textbook, used the same contents, taught the concepts in the same order and gave the similar tests and examinations. The only difference is that one class used the e-homework system and the other did not use the e-homework system. A survey containing fifteen questions was posted online in the online Homework site.

\section{Research Methods}

We embarked on an exploratory research. Data were collected from the Fall 2009 and the Fall 2010 classes in Introductory Business Statistics, a required course for all first year Bachelor of Commerce (B.Com.) students studying at a Canadian university.

Table 1: Course Composition

\begin{tabular}{lll}
\hline \multicolumn{1}{c}{ Course Structure } & Year 2009 (with no e-homework) & \multicolumn{1}{c}{ Year 2010 (with e-Homework) } \\
\hline Course evaluation & 2 quizzes $(12 \%$ and 13\%) & 2 quizzes $(10 \%$ and 10\%) \\
& Term Test $(25 \%)$ & Term Test $(25 \%)$ \\
& Final Exam (50\%) & 11 Assignments Online Homework (5\%) \\
& & Final Exam (50\%) \\
Class Structure & 3 hours lecture & 3 hours lecture \\
\hline
\end{tabular}

We adopted the e-Homework system in 2010 to a large class size of 744 students. The class in 2009 did not utilize the e-Homework system. For the class of 2010, 123 students (16.5\%) have dropped the course before completing the course as shown in Table 2. The course drop rate is higher in 2009 than in 2010, which seemed to suggest that the online homework is helping the students learn Business Statistics. In 2009, we had 711 students enrolled in the Introductory Business Statistics course. The 2009 and 2010 classes used the same course outline that included the same evaluation components as shown in Table 1, the same textbook, and the same course content. The course concepts were taught in the same sequence. The test and examinations were also similar. The only difference was that the class with 744 students was required to use the e-homework system while the other class with 711 enrolled, was not required to use the e-homework system. For the class that does not required the e-Homework, the e-Homework component weight of $5 \%$ was re-distributed to the two quizzes as shown in Table 1.

We surveyed the class that used the e-homework system. The questionnaire was comprised of fifteen questions which were intended to measure the students' attitudes toward the online homework system. The survey was posted on the e-homework system site. 
Table 2: Classes Characteristics

\begin{tabular}{lcc}
\hline \multicolumn{1}{c}{ Class } & $\begin{array}{c}\text { Year 2009 (with no e- } \\
\text { homework) }\end{array}$ & Year 2010 (with e-Homework) \\
\hline Number of students & 711 & 744 \\
enrollment & $131(18.4 \%)$ & $123(16.5 \%)$ \\
$\begin{array}{l}\text { Number of students who } \\
\text { dropped the course }\end{array}$ & 580 & 621 \\
Number of students remaining & & \\
\hline
\end{tabular}

\section{Research Findings}

\section{Student Performance}

Hypothesis 1: There is difference in final marks between the class with e-homework and the class without ehomework.

Table 3: Comparison of Final Marks between class with e-homework and class without e-homework

\begin{tabular}{lcc}
\hline \multicolumn{1}{c}{ Class } & Year 2009 (with no e-Homework) & Year 2010 (with e-Homework) \\
\hline Number of students & 580 & 621 \\
remaining & & \\
Mean Final marks & 62.01 & 66.98 \\
Standard Deviation & 15.40 & 14.28 \\
\hline
\end{tabular}

The final marks for the two classes are summarized in Table 3. The class of 580 students who were subjected to the e-Homework system has the average final marks of $66.98 \%$. The other class of 621 students were not subjected to the e-Homework system has an average final marks of $62.01 \%$. The average final marks of the two classes were significantly different ( $p$-value $<0.000$; $t=-5.795$ ). The average final marks of the class with e-homework are higher than the average final marks in the class without e-homework. These findings provide the evidence to demonstrate that the e-homework system is effective.

Hypothesis 2: There is relationship between grade distribution and type of class (class with e-homework and class without e-homework)

The grade distributions of the two classes are summarized in Table 4. In the class with e-Homework system, $19.6 \%$ of the students earned an A grade, $25.4 \%$ students earned a B grade, $25.6 \%$ students earned a C grade, $15.6 \%$ students earned a D grade, and $13.7 \%$ students earned grade an F. In the class with no e-homework system, 7.8\% students earned an A grade, $23.1 \%$ students earned a B grade, $32.1 \%$ students earned a C grade, $20.7 \%$ students earned a D grade, and $20.7 \%$ students earned grade an $\mathrm{F}$. These findings indicate that there is a relationship between the grade distribution of a class and the type of class $(\mathrm{p}<0.000, \chi 2=41.230)$. As shown in Figure 1, the percentages of students who obtained an A grade and a B grade are higher in the class with ehomework than in the class without e-homework. The percentages of students who obtained $\mathrm{C}, \mathrm{D}$, and $\mathrm{F}$ grades are higher in the class without e-homework than in the class with e-homework. These findings suggest that the e-homework is effective in reducing the failure rate.

Table 4: Comparison of Grade Distribution in Class with e-Homework and Class without e-Homework

\begin{tabular}{|c|c|c|}
\hline \multirow{2}{*}{ Final Grade } & \multicolumn{2}{|c|}{ Online Homework } \\
\hline & $\begin{array}{l}\text { Class with e-Homework } \\
(n=621)\end{array}$ & $\begin{array}{l}\text { Class without e-Homework } \\
(n=580)\end{array}$ \\
\hline 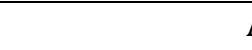 & $19.6 \%(122)$ & $7.8 \%(45)$ \\
\hline 1 & $25.4 \%(158)$ & $23.1 \%(134)$ \\
\hline ( & $25.6 \%(159)$ & $32.1 \%(186)$ \\
\hline 1 & $15.6 \%(97)$ & $20.7 \%(120)$ \\
\hline 1 & $13.7 \%(85)$ & $16.4 \%(95)$ \\
\hline
\end{tabular}


Figure 1: Grade Distributions for class with e-homework and class without e-homework

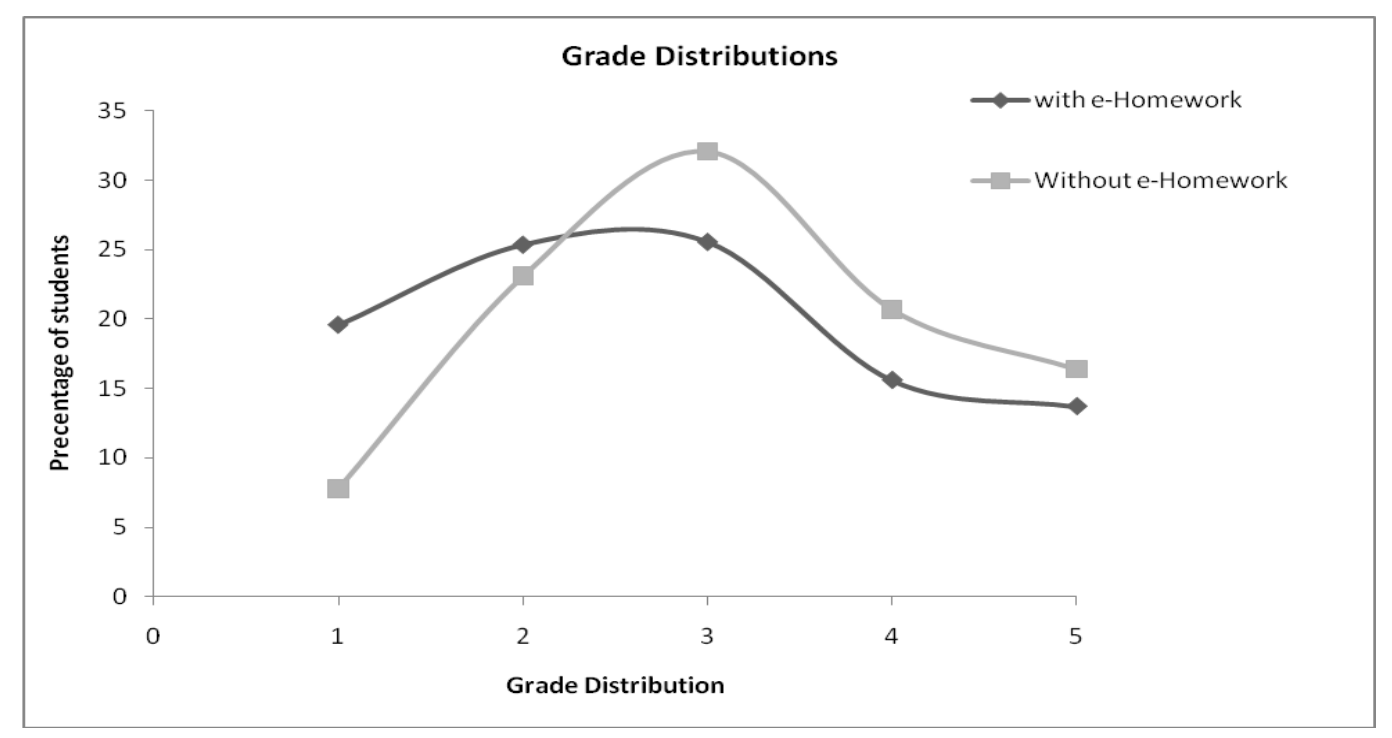

Note: The values shown for grade distributions represent grades as follows: 1 denotes A grade, 2 denotes B grade, 3 denotes $\mathrm{C}$ grade, 4 denotes $\mathrm{D}$ grade and 5 denotes $\mathrm{F}$ grade.

In Figure 1 the distribution of A and B grades are higher for the class with e-Homework system than that of the class without e-Homework system. The distribution of C, D and F grades are lower for the class with eHomework system than that of the class without e-Homework system.

Hypothesis 3: The participation rate for the e-homework has an impact on the final grade.

We found that the participation rate is positively correlated with the final grade $(p<0.000, r=0.538)$. For students with participation rate of less than $50 \%$, the average final mark is $43 \%$ which is a failure grade as shown in Table 5. For students with participation rate of more than 50\%, the average final mark is $60 \%$ which is a C grade. We then tested for within subjects' performance; that is we examined whether students scored high marks (above 70\%) on the online homework also had a higher final grades. Pearson's correlation coefficient $(0.444)$ is significant at 0.01 level $(\mathrm{p}<0.000)$. This suggests that the online homework certainly benefited the students who devoted their effort doing homework online.

Table 5: Participation Rate and Average Final Marks

\begin{tabular}{lcl}
\hline Participation Rate & Average Final Marks & Grade \\
\hline Less than 50\% participation rate & $43 \%$ & $\mathrm{~F}$ \\
More than 50\% participation rate & $60 \%$ & $\mathrm{C}-$ \\
\hline
\end{tabular}

\section{Students' Perception}

Hypothesis 4: The proportion of students who are satisfied with the online homework system is more than half.

The results of the survey indicate that more than half the students (64\%) are satisfied with the e-homework $(\chi 2=2.951, \mathrm{p}<0.086)$. The e-homework system appeared to motivate peer learning and consultation in that $58 \%$ of the students report working together 2 to 3 times during the semester on the assigned homework; $27 \%, 4$ to 5 times, $10 \%, 6$ to 7 times; and 5\%, more than 7 times. In terms of the Website itself, $51 \%$ rate the overall content above "good" and $42 \%$ rate it as average. Only $7 \%$ say it is below average. Overall $61 \%$ of the students would recommend the e-homework to a friend. 
The results of student's perception on the usefulness of the e-homework are summarized in Table 6 and Figure 2. We use a 5-point scale to measure the student's perception, that is, 5 means 'strongly agree', 4 means 'somewhat agree', 3 means 'neither agree nor disagree', 2 means 'somewhat disagree' and 1 means 'strongly disagree'. Overall, the scores (shown in the Radar Chart, see Figure 2) are all above 3 which means that most of students perceive that the e-homework is useful in helping them feel better prepared for writing tests, understand concepts, receive timely feedback, generate discussion of statistics among peers, develop good study habits and promote higher confidence in dealing with the statistical concepts.

Table 6: Student's Perception on the Usefulness of the Online Homework

\begin{tabular}{lcc}
\hline Features & Mean & Std. Deviation \\
\hline Better Prepared & 3.39 & 1.412 \\
Helps Understanding the concepts & 3.53 & 1.358 \\
Timely Feedback & 3.88 & 1.122 \\
Classmates Helpful & 3.85 & 0.882 \\
Good Study Habits & 3.61 & 1.202 \\
Confident about the statistical concepts & 3.73 & 0.975 \\
\hline
\end{tabular}

Entwistle (1997) and Prosser \& Trigwell (1998) have made the distinctions between deep and surface learning. The e-homework system is focused on encouraging deep learning in that students have to understand the concepts in order to answer the questions. Since each question is generated individually, students cannot simply copy the right answers from each other, consequently, peer help has to take place at a conceptual level. This online system also seems to enable scaffolding, a mechanism by which a learner at one level receives support from another learner who is at another level (Bliss et al. 1996). Students who are faced with incremental conceptual challenges can access their peers for help (Vygotsky, 1978). Another important feature of the online system is its capacity to cultivate deep learning by means of generating immediate feedback. This feature is essential to help the learner confirm their understanding of the new knowledge (Svinicki, Hagen, and Meyer, 1996). Hyland (2000) asserts that incorporating frequent homework assignments as part of a formative assessment strategy provides important feedback that can be used to further develop learning.

\section{Figure 2: Radar Chart on Students' Perception on the Usefulness of Online Homework}

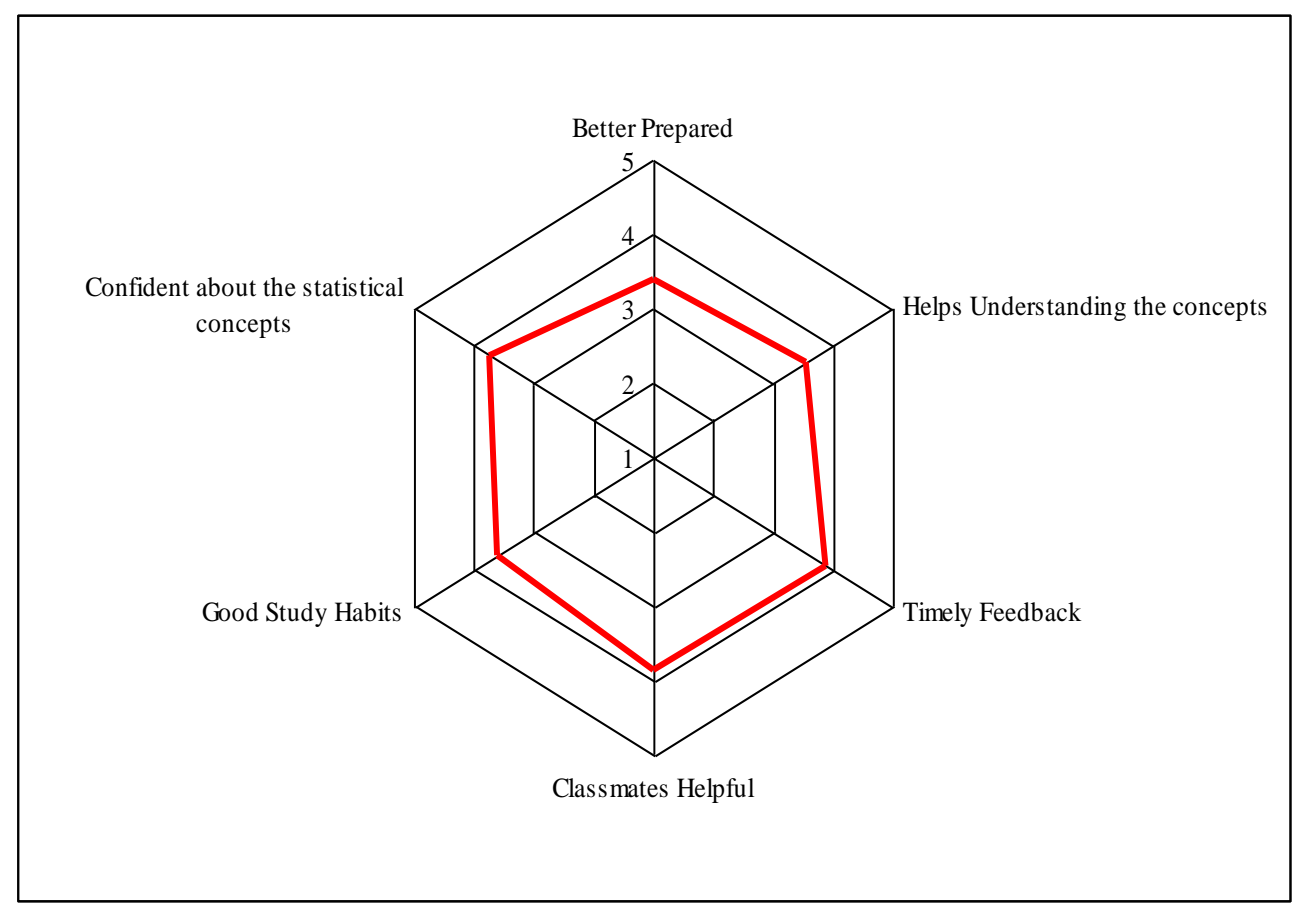




\section{Conclusion and Recommendations}

The online homework system with its dynamic content features has the potential for encouraging and enhancing deep learning among undergraduate commerce students in business statistics courses. This webbased system enables learning through individualized content, immediate feedback, incremental concept development, and a favorable environment for peer assistance. Both students and professors benefit from the e-homework. Students achieve enhanced understanding of Introductory Business Statistics, as indicated by the improved performance of those who were diligent about completing their homework. Professors also obtain immediate feedback about the level of students understanding on a particular topic. This is critical to teaching in general, since most instructors know that some concepts are more difficult for students to grasp than other topics and armed with this feedback, the professor can spend more time on the more challenging concepts. The online system feedback also alerts the professor about the need for review and/or remedial instruction before introducing a new concept. This allows review and revision to occur sooner rather than later in the semester. In addition, because these homework exercises are marked online, professors have more time to provide one-on-one assistance for the students who require that level of help. This type of dynamic system has particular application in a large class setting where students can be anonymous and it is more difficult for professors to determine when students are experiencing conceptual difficulties. Professors no longer have to wait for the results of traditional test and examinations to identify the level of student knowledge and understanding

This paper addresses the question: Can an e-homework system improve the performance of large undergraduate classes (greater than 600 students) in Introductory Business Statistics? Our research shows that e-homework is effective in terms of improving the final grades, increasing the percentage of the class average, decreasing the failure rate, and increase overall student participation. Furthermore based on the survey students felt the online system enhanced preparation for writing tests, the availability of immediate feedback increased their understanding of concepts, encouraged discussion of statistics among peers, cultivated stronger study habits, and developed a higher level of confidence in applying with the statistical concepts.

We conclude that for large classes where resources are limited, it is a good idea to automate the homework so that students can have timely feedback on their performance. The nature of feedback motivates and engages them in learning. However, there is a limitation of our research. Although this research is not an ideal experimental-control group design because of the number of other variables which were not controlled that could have influenced final grades, we did compare the performance of two classes in the Introductory Business Statistics course. Future improvements to the system may include the utilization of a variety of other multimedia resources such as video, the introduction of comprehensive grade-book tracking, and setting up the option for self-paced learning. All of these improvements have the potential to further enhance deep learning.

\section{References}

Allain, R., and Williams, T. (2006). The Effectiveness of Online Homework in an Introductory Science Class. Journal of College Science Teaching, 35 (6), 28-30.

Biktimirov, E. N., and Klassen, K. J. (2008). Relationship between the Use of Online Support Materials and Performance in the Introductory Finance Class. Journal of Education for Business, 83(3), 153-158.

Bliss, J., Askew, M., and Macrae, S. (1996). Effective Teaching and Learning: Scaffolding Revisited. Oxford Review of Education, 22(1), 37-61.

Bonham, S. W., Beichner, R. J., and Deardorff, D. L. (2001). Online homework: Does it make a difference? The Physics Teacher, 39, 293-296.

Bonham, S. W., Deardorff, D. L., and Beichner, R. J. (2003). Comparison of Student Performance Using Web and Paper-based Homework in College-level Physics. Journal of Research in Science Teaching, 40(10), 1050-1071.

Brightman, H. (1977). An evaluation of two models of undergraduate statistics. Decision Sciences, 8, 287-299. 
Burch, K. J., and Kuo, Y. (2010). Traditional Vs. Online Homework in College Algebra. Mathematics and Computer Education, 44, 53-63.

Cheng, K. K., Thacker, B. A., Cardenas R. L., and Crouch, C. (2004). Using an online homework system enhances students' learning of physics concepts in an introductory physics course. American Journal of Physics, 72(11), 1447-1453.

Cole, R. S., and Todd, J. B. (2003). Effects of Web-Based Multimedia Homework with Immediate Rich Feedback on Student Learning in General Chemistry. Journal of Chemical Education, 80(11), 1338-1343.

Cooper, H., Robinson, J. C., and Patall, E. A. (2006). Does homework improve academic achievement? A synthesis of research, 1987-2003. Review of Educational Research, 76(1), 1-62.

Cooper, S. T., Tyser, R. W., and Sandheinrich, M. B. (2007). The Benefits of Linking Assignments to Online Quizzes in Introductory Biology Courses. Journal of Online Learning and Teaching, 3(3), 217-221.

Cudd, M., Tanner, J., and Lipscomb, T. (2004). An Empirical Analysis of a Cumulative/Rework Testing Strategy: It's Effect on Student performance in Principles of Finance. Journal of Financial education, 30(Winter), 16-31.

Dillard-Eggers, J., Wooten, T., Cholds, B., and Coker, J. (2008). Evidence on the Effectiveness of On-line Homework. College Teaching Methods and Styles Journal, 4(5), 9-15.

Dufresne, R., Mestre, J., Hart, D. M., and Rath, K. A. (2002). The Effect of Web-based Homework on Test Performance in Large Enrollment Introductory Physics Courses. Journal of Computers in Mathematics and Science Teaching, 21(3), 229-251.

Entwistle, N. (1997). Contrasting Perspectives on Learning. In the Experience of Learning: Implications for Teaching and Studying in Higher Education. Marton, F., Hounsell, D., and Entwistle, W.J. (ed.) $2^{\text {nd }}$ Edition. Edinburgh: Scottish Academic Press, 3-22.

Garfield, J., Hogg, B., Schau, C., and Whittinghill, D. (2002). First Courses in Statistical Science: The Status of Educational Reform Efforts. Journal of Statistics Education, 10(2), 456-467.

Glass, J., and Sue, V. (2008). Student Preferences, Satisfaction, and Perceived Learning in an On-line Mathematics Class. Journal of Online Learning and Teaching. 4(3), 325-338.

Hall, R. W., Butler, L. G., McGuire, S. Y., McGlynn, S. P., Lyon, G. L., Reese, R. L. and Limbach, P. A. (2001). Automated, Web-Based, Second-Chance Homework, Journal of Chemical Education, 78(12), 17041708.

Harrington, C. F., and Schibik, T. J. (2004). Methods for Maximizing Student Engagement in the Introductory Business Statistics Course: A Review. Journal of American Academy of Business, 4(1), 360-364.

Hauk, S., and Segalla, A. (2005). Student perceptions of the web-based homework program Web Work in moderate enrollment college algebra classes. Journal of Computers in Mathematics and Science Teaching, 24(3), 229-253.

Houts, L. M., and Taylor J. C. (2008). Assignment Of Grades And Student. Performance In A Hybrid Operations Management Course: What Works And Ideas For Improvements. Journal of College Teaching and Learning, 5(3), 61-68.

Hyland, P. (2000). Learning From Feedback on Assessment. In: A. Booth and P. Hyland, eds. The Practice of University History Teaching. Manchester UP. 233-247.

Jordan, W. E., and Stroup, D. E. (1984). The Image of Statistics. Collegiate News \& Views Spring, 11-13.

Johnston, T. C. (2004). Online Homework Assessments: Benefits and Drawbacks to Students. Academy of Educational Leadership Journal, 8(3), 29-40.

Kimberly J. B., and Kuo, Y. J. (2010). Traditional vs. Online Homework In College Algebra. Mathematics and Computer Education, Old Bethpage, 44(1), 53-64.

Kortemeyer, G. (2006). An Analysis of Asynchronous Online Homework Discussions in Introductory Physics Courses. American Journal of Physics, 74 (6), 526-536.

Lane, M. S., Mansour, A. H, and Harpell, J. I. (1993). Operations Research Techniques: A longitudinal Update 1973-1988, Interfaces, 23(2), 63-68.

Lee, F. L., and Heyworth, R. M. (1997). Computer Diagnosis of Composed Errors in Solving Logarithms Problems. In Proceedings of Global Chinese Computer Conference of Education '97, ed. K.D. Li, and K. K He. Beijing: Beijing Normal University Press.

Lee, W., Courtney, R.H., and Balassi, S. J. (2010). Do Online Homework Tools Improve Student Results in Principles of Microeconomics Courses? American Economic Review, 100(2), 283-286.

Packard, A. L., Holmes, G. A., and Fortune, J.C. (1993). A Comparison of Three Presentation Methods of Teaching Statistics. ERIC Document Reproduction Service No. 365 696, Chicago, IL. 
Palocsay, S. W., and Stevens, S. P. (2008). A Study of the Effectiveness of Web-based Homework in Teaching Undergraduate Business Statistics. Decision Sciences Journal of Innovative Education, 6(2), 213-232.

Peng, J. (2009). Using online homework system to submit accounting homework: the role of cognitive need, computer efficacy, and perception. Journal of Education for Business, 84(5), 263-268.

Peng, Z. (2006). Applying Internet-based Technologies to Teaching Corporate Finance and Investments. Journal of Educators Online, 3(6), 1-18.

Penn, J. H., Nedeff, V. M., and Gozdik, G. (2000). Organic Chemistry and the Internet: A Web-based Approach to Homework and Testing Using the WE LEARN System. Journal of Chemical Education, 77(2), 227-31.

Peters, M., Kethley, B., and Bullington, K. (2002). The relationship between homework and performance in an introductory operations management course. Journal of Education for Business, 77(6), 340-344.

Philip, G. C., and Schultz, H. K. (1994). Operations Research in Medium-Sized Companies and the Microcomputer Revolution: Educational Implications. Journal of Education for Business, 69(4), 217221.

Prosser, M., and Trigwell, W. (1999). Understanding Teaching and Learning: The Experience of Higher Education. Buckingham, UK: Open University Press.

Rayburn, L. G., and Rayburn, J. M. (1999). The Impact of Course Length and Homework Assignments on Student Performance. Journal of Education for Business. 74, 325-331.

Rhett, A., and Williams, T. (2006). The Effectiveness of Online Homework in an Introductory Science Class. Journal of College Science Teaching, 35(6), 28-30.

Sasser, J. E. (1991). The Effect of Using Computer Tutorials as Homework Assignments on the Mathematics Achievements of Elementary Education Majors. Journal of Computers in Mathematics and Science Teaching, 10(2), 95-102.

Smolira, J. C. (2008). Student's Perceptions of Online Homework in Introductory Finance Courses. Journal of Education for Business, 84(2), 90-95

Svinicki, M. D., Hagen, A. S., and Meyer, K. K. (1996). How research on learning strengthens instruction. In Menges, R. J. and Weimer, M. Teaching on solid ground: Using scholarship to improve practice, San Francisco, CA: Jossey-Bass, 257-288.

Swanson, J. C., Meinhert, D. B., and Swanson, N. E. (1994). Business Communications: A Highly Valued Core Course in Business Administration. Journal of Education for Business. 69(4), 235-239.

Thoennessen, M., and Harrison, M. J. (1996). Computer assisted Assignments in A Large Physics Class. Computers and Education. 27(2), 141-147.

Vygotsky, L. S. (1978). Mind in Society: The Development of Higher Psychological Processes. Cambridge, Harvard University Press.

Wong, C. K. (2001) Attitudes and Achievements: Comparing Computer-based and Traditional Homework Assignments in Mathematics. Journal of Research on Technology in Education, 33(5), 159-176

Zanakis, S. H., and Valenzi, E. R. (1997). Student Anxiety and Attitudes in Business Statistics. Journal of Education for Business, 73(1), 10-15. 